\title{
Mechanical Performance Evaluation of Concrete Beams Strengthened with Carbon Fiber Materials
}

\author{
Jun Ding, ${ }^{1,2}$ Xia Huang, ${ }^{1}$ Gang Zhu, ${ }^{1}$ Song Chen, ${ }^{1}$ and Guochao Wang1 \\ ${ }^{1}$ College of Mechanical Engineering, Chongqing University of Technology, Chongqing 400054, China \\ ${ }^{2}$ Key Laboratory of Manufacture and Test Techniques for Automobile Parts, Ministry of Education, Chongqing 400054, China \\ Correspondence should be addressed to Jun Ding; dingjunawen@126.com
}

Received 16 July 2013; Accepted 12 September 2013

Academic Editor: Xing Chen

Copyright (c) 2013 Jun Ding et al. This is an open access article distributed under the Creative Commons Attribution License, which permits unrestricted use, distribution, and reproduction in any medium, provided the original work is properly cited.

\begin{abstract}
As a kind of novel material of high strength and light weight, carbon fiber materials have been widely used in construction industry to repair the damaged bridges improving its mechanical performance. In this work, the reinforced plates made of carbon fiber materials (for short CFRP) are externally bonded to the bottom of concrete beams to enhance load capacity of beams. The strain energy release rates are calculated at the interest crack in concrete beams based on virtual crack closure technology using FEM and are chosen as the criterion to determine whether the mechanical properties of beams are strengthened by being externally bonded with CFRP. The effects of main crack propagation on plain concrete beam, on concrete beam strengthened with CFRP, and on inclined crack are also discussed. The comparison between the beams with and without CFRP shows that the CFRP significantly increases the loading capacity and crack resistance. It also shows that the main crack propagation can reduce loading capacity and crack resistance regardless of strengthening. The experiment observation also supports this. It proves the validity of the method, and it is concluded that in order to increase the loading capacity and crack resistance effectively, controlling over the crack propagation is necessary.
\end{abstract}

\section{Introduction}

Due to the excellent mechanical properties such as light weight, high strength at tension and superior resistance to aggressive environment, the reinforcement and strengthening technique bonded with the reinforced plates made of carbon fiber materials (for short CFRP) to concrete beam is widely accepted and considered as an effective and convenient method among various methods of strengthening infrastructure construction [1-4]. According to structural mechanics, an important concern over the effectiveness and safety for the method strengthening concrete beam with CFRP is the enormous potential for load capacity and decrease in failure mode in service.

So far, many researches [5-11] have been conducted to investigate the mechanical properties of the retrofitted members externally bonded with CFRP. It can be concluded that the bonding of the CFRP plates has a significant effect on enhancing the overall performance even for plates with a relatively low modulus of elasticity. The strengthening technology externally bonded with CFRP can considerably increase the strength at bending, reduce the deflections as well as crack width in area of tension, and also change the mechanical behavior and failure pattern during service. The researches $[5,8-10]$ demonstrated that the cracking moment in reinforced concrete beams with CFRP can significantly increase by $218 \%$, from $12 \%$ to $230 \%$. They also found that in strengthened flexural members, cracks are seen in bigger numbers and closer to each other; however, they are narrower than in beams without strengthened reinforcement.

However, the review for the previous works shows that the reinforced concrete beams used to be strengthened with CFRP are essentially intact, that is, without any greater cracks and obvious defects in advance. As a matter of fact, some bigger defects and macrocracks such as holes and cracks are already pre-existed in flexural members in construction before it is strengthened. Such imperfection can severely reduce the structural strength and stiffness of members, and it receives more and more attention for earlier design and later maintenance. Moreover, the strengthened member fails often in a brittle way due to the loss of connection between 
composite material and the concrete itself in the process of strengthening. Consequently, it is necessary to consider the effect of pre existed macrocracks on the performance of the flexural members externally bonded with CFRP systematically.

For the convenience of investigating the mechanical properties theoretically, the plain concrete beams, not reinforced with steel bars, have been chosen for this work to examine the mechanical behaviors such as structural strength, stiffness, and strain energy release rates. Considering that the purpose of this work focuses on exploring the loading capacity and crack resistance for the flexural beams externally bonded with CFRP, the choice of the purely plain beam as being studied will not lose the generality of research. In order to emphasize the influence of existence of crack on the loading capacity of beams, the macrocracks with different length were in advance made in the plain concrete beams and subsequent researches serve for it. According to fracture mechanics, in order to predict crack propagation, the strain energy released rate (abbreviated as SERR for convenience of later description), $G$, must be evaluated and compared with the critical fracture energy of the constituent materials, $G_{I C}$, determined from experiments. The calculation for SERR at the interest crack was based on virtual crack closure technology (VCCT) together with the finite element method (FEM). The values for SERR were then selected as a criterion to determine whether the mechanical properties of the beam are strengthened by being externally bonded with CFRP in comparison to those beams without bonded CFRP. We focus upon the effect of crack propagation that occurred at the initial crack, edge crack, and the mutual interaction between them on the loading capacity and failure mechanism of strengthened with CFRP.

\section{Materials and Methods}

2.1. The Description in the Model of the Concrete Beam. In order to experimentally investigate the improvement in mechanical properties of concrete beams due to the bond of CFRP, our previous work [11] made some experiments for beams at the test setup, as shown in Figure 1. Figure 2(a) shows the failure mode of the concrete beam without CFRP strengthened, and Figures 2(b)-2(d) show the failure mode with CFRP strengthened for the length of $0.1 \mathrm{~m}, 0.2 \mathrm{~m}$ and $0.35 \mathrm{~m}$, respectively.

According to the previous experimental measurement, the geometry model has been constructed, shown as in Figure 3(a). It includes two models, plain concrete beam with and without CFRP. The geometry dimension for the concrete beam is about $0.1 \mathrm{~m} \times 0.1 \mathrm{~m} \times 0.4 \mathrm{~m}$ each with an initial crack length of $20 \mathrm{~mm}$, marked as $a_{0}$ in Figure 3. The plain concrete beam externally bonded with CFRP is illustrated as in Figure 3(b). In experiment test, the length of the CFRP varies with the different case study to investigate the effect of the length of CFRP on the reinforcement. The details about the experiment can refer to the work [11].

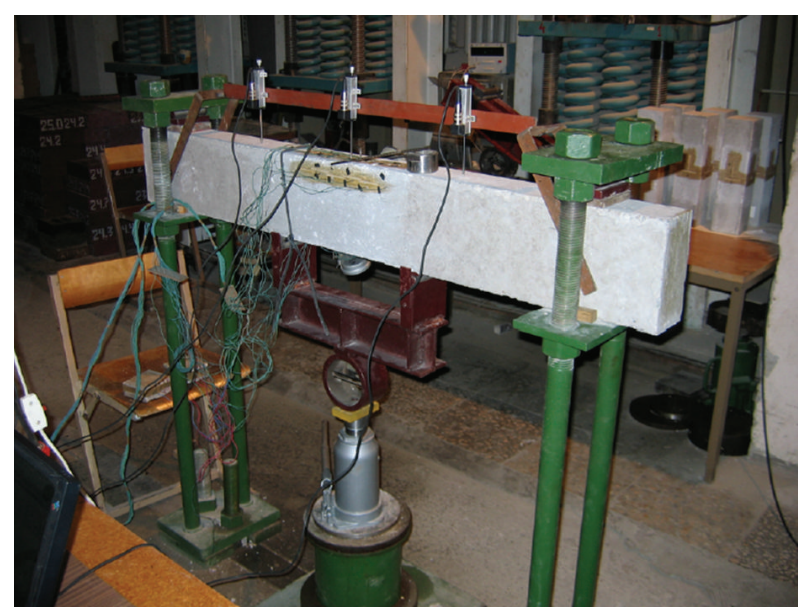

FIGURE 1: The test setup for concrete beams.

2.2. The Crack Criterion Based on SERR. There are common three fracture criteria, $K$ (stress intensity factor), J integral, and Strain Energy Release Rate (SERR) in linearly elastic fracture mechanics, which are used to determine whether and when crack propagates [12]. The critera for both $K$ and SERR are for linearly elastic material, while $J$ is integral criterion for plastic material. Concrete behaves in brittle material behavior and it is considered as elastic material [13]. Generally, in numerical simulation, the calculation for the value of $K$ requires strict conditions for the mesh to discrete the geometry model, especially at the tip of the crack, due to its numerical radius singularity [12]. Meanwhile, the calculation for SERR usually does not need a more special element type near the area around crack tip, and it even employs fewer elements.

The SERR refers to the energy dissipated during fracture per unit of newly created fracture surface area, which is an essential quantity in fracture mechanics because the energy that must be supplied to a crack tip for it grows must be balanced by the amount of energy dissipated due to the formation of new surfaces [12].

For calculation, SERR is defined as

$$
G=-\frac{\partial(U-V)}{\partial A},
$$

where $U$ is the potential energy available for crack growth, $V$ is the work associated with any external forces, and $A$ is the crack area (crack length for two-dimensional problems). The failure criterion of energy release rate states that the crack will grow when the available energy release rate $G$ is greater than or equal to the critical value $G_{C}$. The quantity $G_{C}$ is the fracture energy and is considered to be a material property which is independent of the applied loads and the geometry configuration of the body.

For two-dimensional geometry configuration with isotropic elastic material property, the value of $K$ and SERR for the case of problem of plane strain can follow (2), where $K_{I}$ is the stress intensity factor, $E$ is Young's modulus, and $v$ is the Poisson ratio. $G$ is the fracture energy and is considered to be 


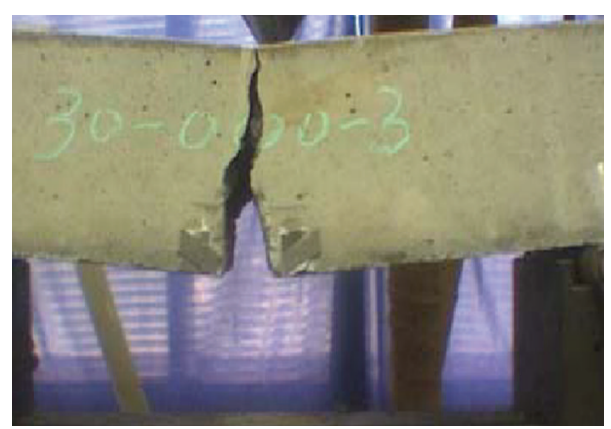

(a)

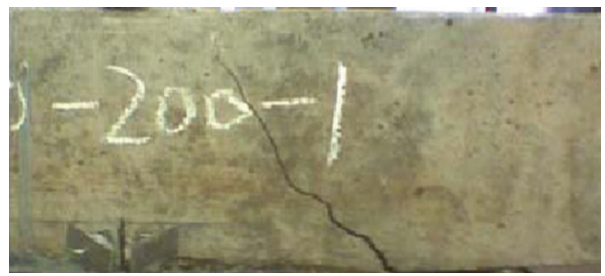

(c)

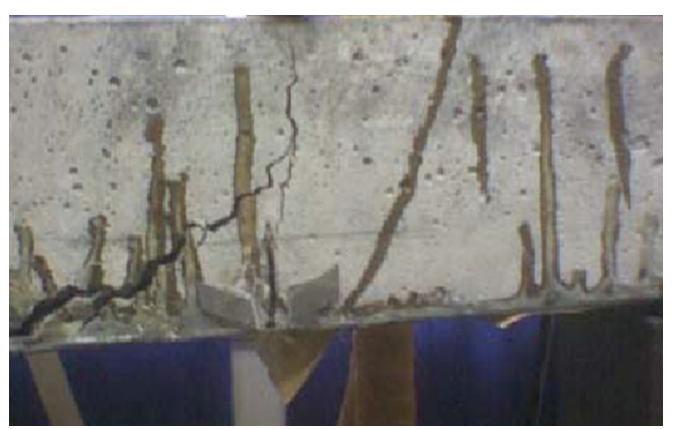

(b)

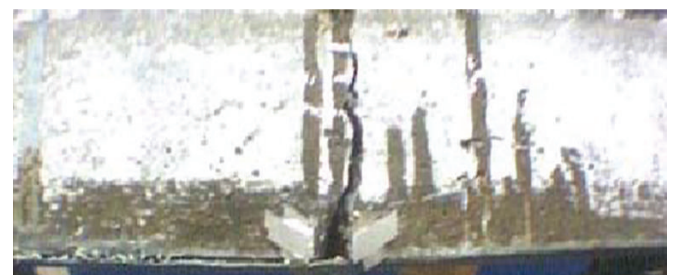

(d)

FIGURE 2: The photos of experimental measurement [11]. (a) Failure mode of the beam without CFRP. (b) Failure mode of the beam with CFRP of $0.1 \mathrm{~m}$. (c) Failure mode of the beam with CFRP of $0.2 \mathrm{~m}$. (d) Failure mode of the beam with CFRP of $0.35 \mathrm{~m}$.

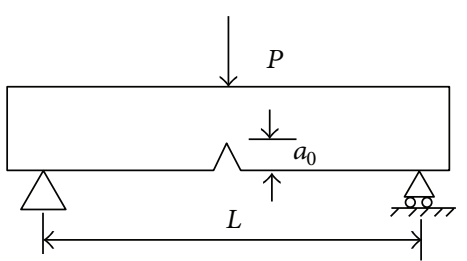

(a)

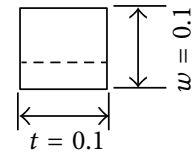

FIGURE 3: The geometrical model of the concrete beam. (a) The plain concrete beam. (b) The beam strengthened with CFRP.

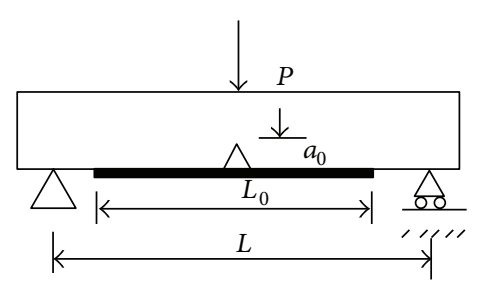

(b)

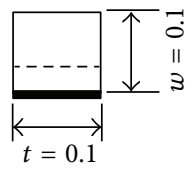

FIGURE 3: The geometrical model of the concrete beam. (a) The plain concrete beam. (b) The beam strengthened with CFRP.

a material property which is independent of the applied loads and the geometry configuration of the body. Consider

$$
G=\frac{K_{I}^{2}}{E}\left(1-v^{2}\right)
$$

For the three-point bending concrete beam, illustrated as in Figure 3, the expression calculating the value for $K_{I}$ follows (3), wherein $P$ is the load applied at the midspan of the concrete beam, $S$ is the span distance between two supports of the concrete beam, $t$ is the thickness of the concrete beam, $a$ is the crack length, and the expression for $F(\alpha)$ can follow (4). Consider

$$
\begin{gathered}
K_{I}=\frac{3 S P}{2 t W^{2}} \sqrt{\pi a} F(\alpha), \\
F(\alpha)=\frac{1.99-\alpha(1-\alpha)\left(2.15-3.93 \alpha+2.7 \alpha^{2}\right)}{\sqrt{\pi}(1+2 \alpha)(1-\alpha)^{3 / 2}}, \\
\text { where } \alpha=\frac{a}{w} .
\end{gathered}
$$

In a word, for the geometric configuration illustrated as in Figure 3, the value of $K$ can be numerically calculated by substituting the parameters such as the crack length, the width of the cross section, the span between supports, and the load. Then taking on (2) can derive the value of SERR.

2.3. The Virtual Crack Closure Technique (VCCT). The virtual crack closure technique (VCCT) is widely used for computing SERR based on results from finite element analysis to supply the mode separation required when using the mixed-mode fracture criterion [14].

This method is mainly based on Irwin's crack closure integral and on the assumption that the energy $\Delta E$ released when the crack is extended by $\Delta a$ from $a$ to $a+\Delta a$ is identical to the energy required to close the crack between locations $l$ and $i$, as illustrated in Figure 4. Additionally, however, it is assumed that a crack propagation of $\Delta a$ from $\Delta a$ to $a+\Delta a$ (node $i$ ) to $a+2 \Delta a$ (node $k$ ) does not significantly alter the state at the crack tip. Therefore, when the crack tip is located at node $k$, the displacements behind the crack tip at node $i$ are approximately equal to the displacements behind the crack tip at node $l$ when the crack tip is located at node $i$. Further, the energy $\Delta E$ released when the crack is extended by $\Delta a$ from 


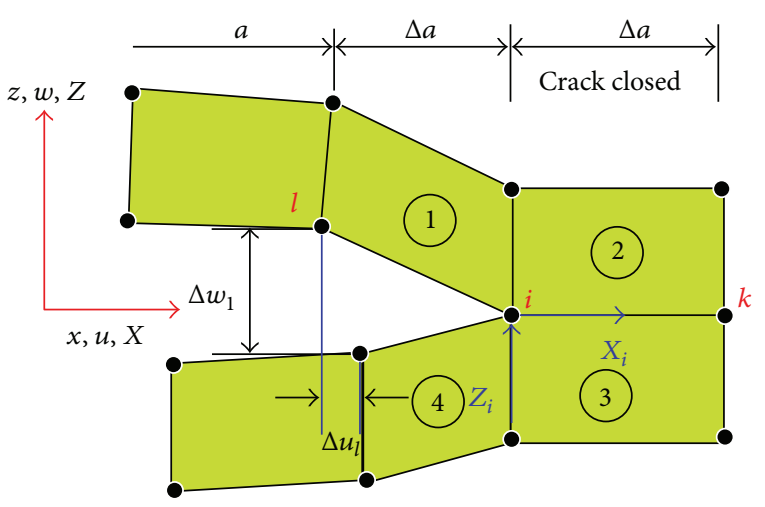

FIgURE 4: The specimens were tested in the three-point bending configuration, and the load was applied with cylindrical rollers as line load across the top width of the beams. To spread the load and avoid stress concentrations, elastomeric pads were placed between the roller supports and the lower surface of the specimens and between the loading device and the top surface of the specimens. During experimental measurement, the ultimate load which makes crack propagate or makes the reinforced concrete beam fail in fiber, in concrete, or at the interface between them can be achieved according to instrument reading. Virtual crack closure technique (VCCT).

$a+\Delta a$ to $a+2 \Delta a$ is identical to the energy required to close the crack between locations $i$ and $k$.

For a crack modeled with two dimensional, four-node elements, as shown in Figure 4, the work $\Delta E$ required to close the crack along one element side therefore can be calculated as follows

$$
\Delta E=\frac{1}{2}\left[X_{i} \Delta u_{l}+Z_{i} \Delta w_{l}\right],
$$

where $X_{i}$ and $Z_{i}$ are the shear and opening forces at the nodal point $i$ and $\Delta u_{l}$ and $\Delta w_{l}$ are the shear and opening displacements at node $l$ as shown in Figure 4. Thus, forces and displacements required to calculate the energy $\Delta E$ to close the crack may be obtained from one single finite element analysis.

However, Figure 3(a) shows that the dominant separation mode at the central crack of the concrete beam should be mode $I$ crack. The term of shearing force $X_{i}$ and of shear displacement $\Delta u_{l}$ can disappear in (5), only the terms for opening force and displacement leave in the equation. Meanwhile, in Figure 3(b), both opening and shearing effects must be taken into account when calculating SERR for the crack failure that occurred at the interface between concrete and CFRP and the failure at the bottom of CFRP.

2.4. Calculation of SERR Based on VCCT. In this section, we discuss the scheme employed to calculate SERR from finite element analysis based on VCCT. The finite element model has firstly been created in ABAQUS software [15]. Because the calculation for SERR based on VCCT only involves the nodal forces and nodal displacements at the element side, more refined mesh or special treatment element types are not necessary for the discretization in FEM at the crack tip. The fewer elements with four-node plane strain elements are used at the crack tip.
TABLE 1: The value of SERR for various numbers of elements.

\begin{tabular}{lcccc}
\hline Numbers of elements & 300 & 600 & 1000 & 1400 \\
\hline SERR from FEA & 10.404 & 9.819 & 9.232 & 9.047 \\
Relative error & $15.3 \%$ & $8.83 \%$ & $2.32 \%$ & $0.265 \%$ \\
\hline
\end{tabular}

The details of mesh configuration around the crack tip are also expressed as in Figure 4. The location of $i$ is the crack tip. In ABAQUS software, in order to obtain the value of nodal force at node $i$, it needs define elements 1 and 2 as one element set using command *ELSET, and using ${ }^{*} \mathrm{EL}$ PRINT command to output the nodal force. Since the node $i$ is shared by elements 1 and 2 , the total nodal force at node $i$ in $Z$ direction is the sum of the contribution at node $i$ by element 1 and that at node $i$ by element 2 . The displacements in $Z$ direction at node $l$ can also be known in finite element analysis. Thus, SERR at the crack tip based on VCCT using finite element analysis can be easily calculated.

In this case, the load applied on the concrete beam is $5000 \mathrm{~N}$, and the crack length is $20 \mathrm{~mm}$, taken into (2)-(4), the value of SERR $G$ is $9.024 \mathrm{~J} / \mathrm{m}^{2}$. In order to check the mesh dependency on computation, four various numbers of elements, 300,600, 1000, and 1400, are used to discrete the plain concrete beam in FEA. The calculated SERR for different numbers of elements is summarized in Table 1. Comparison between the value for SERR from FEA and theoretical calculation indicates that 1400 elements are the best choice which results in the minor error with the theoretical one.

\section{Results and Discussion}

3.1. The Effect of Main Crack Propagation. Firstly, the effects of crack propagation for the main crack seam (the location illustrated as in Figure 3(a)) on the overall strength of the plain concrete beam (i.e. without externally bonded CFRP at the bottom of the beam) are studied as follows. The finite element analysis for the concrete beam under three different loading case is performed in advance, and then the calculation method the same as that previously described in Section 2.4 is employed to calculate the value of SERR. The initial crack length is taken as $20 \mathrm{~mm}$. We model the main crack propagation by means of varying the lengths of cracks, $20,25,30,35$, and $40 \mathrm{~mm}$ to simulate crack growth in service.

Figure 5 shows the plot of the calculated SERR for various load cases against the crack propagation of the main crack. Suppose that crack extends under the load from $20 \mathrm{~mm}$ to $40 \mathrm{~mm}$. It can be seen from the figure that SERR for any case of load can increase slightly with the main crack propagation. The bigger the magnitude of SERR is, the closer it approaches $G_{C}$ of the concrete material. It implies that the strength of the beam decreases with the increase of SERR. For a certain fixed crack length, the value for SERR also increases with the load, which indicates that the bigger load applied at the concrete beam can reduce the loading capacity and make the concrete beam closer to the critical load.

According to Section 3.1, SERR will increase with the load applied to the beam and also with the crack propagation. 


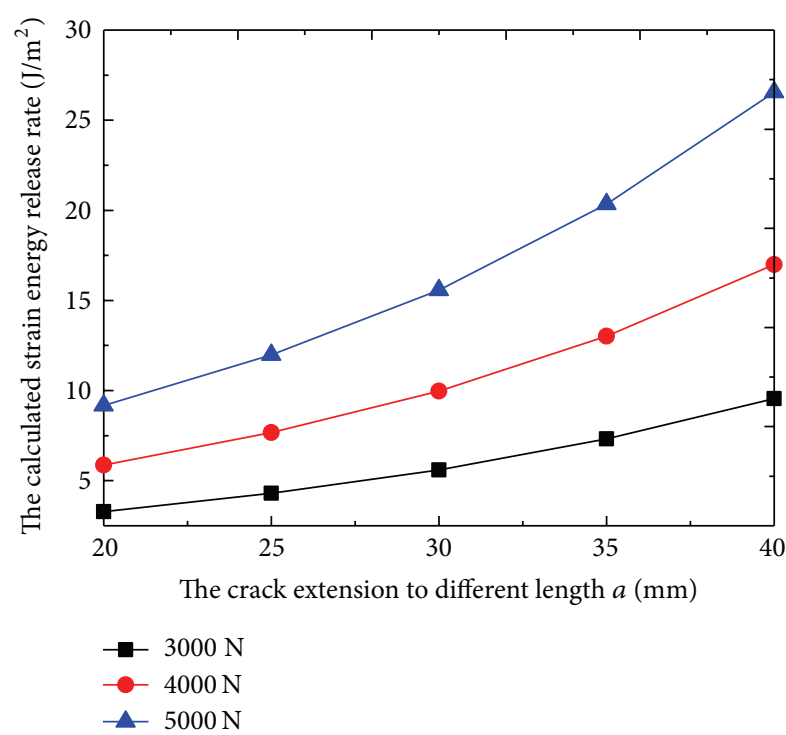

FIGURE 5: The plot of calculated SERR against the main crack propagation.

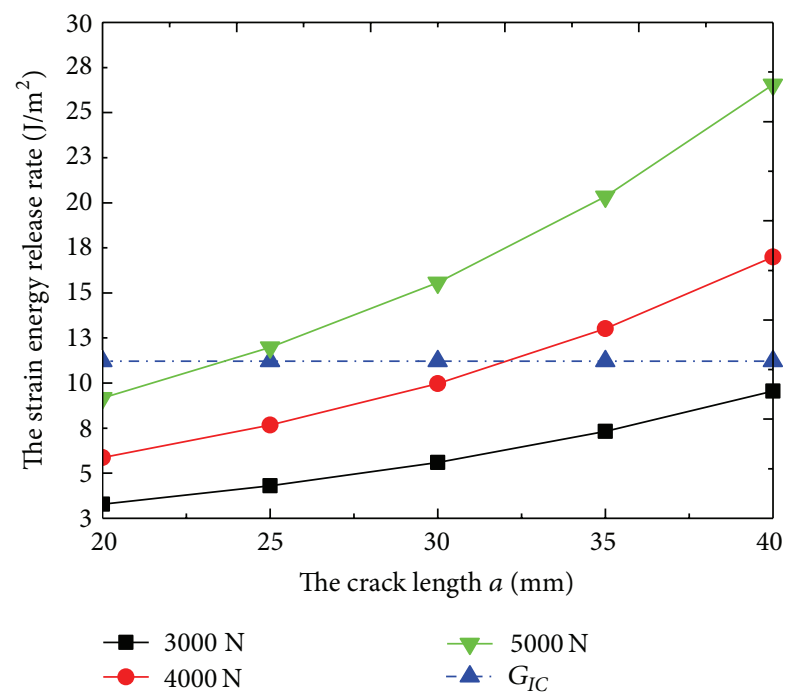

FIGURE 6: The comparison of SERR between the different load and the critical case.

Figure 6 shows a comparison made between the value of SERR for various loads and the critical SERR. For the crack length of $20 \mathrm{~mm}$, the crack propagation will not occur even if the load exceeds $5000 \mathrm{~N}$. However, as the crack length increases, the magnitude of load at which SERR exceeds $G_{I C}$ decreases significantly indicating that the load capacity of the beam weakens.

3.2. The Prediction for the Critical Load. According to Figure 6 , it can be seen that for a given length of crack, the ultimate load applied at the plain concrete beam can be predicated in theory. Figure 7 shows the calculated SERR for various loads at the crack length of $20 \mathrm{~mm}$. The formula that

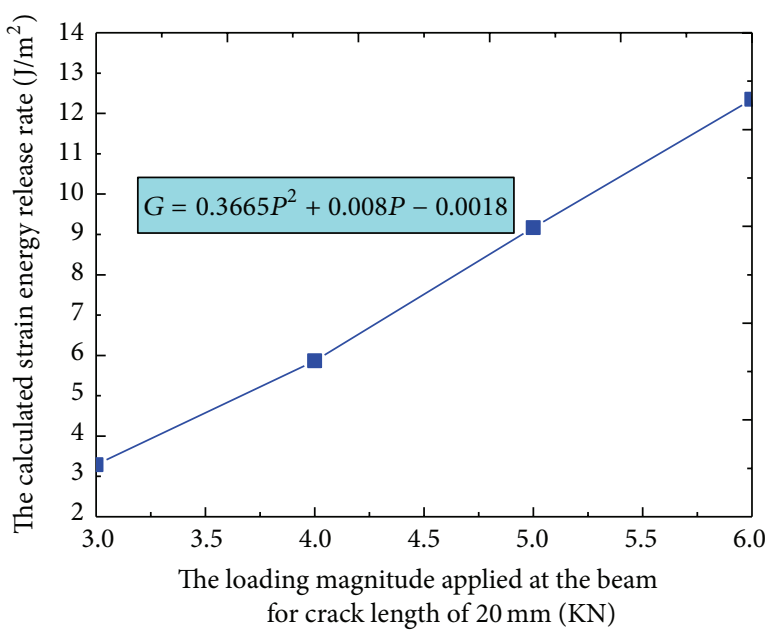

FIgURE 7: The calculated SERR for different load at the crack length of $20 \mathrm{~mm}$.

calculates the ultimate load could be derived based on curve fitting. Consider

$$
G=0.3665 P^{2}+0.0008 P-0.0018 .
$$

The magnitude of ultimate load can be calculated when the value of $G \geq G_{I C}$. Then we can derive the magnitude of load is $5580 \mathrm{~N}$ which makes the initial crack propagates. It is close to the value of $5752 \mathrm{~N}$ observed from the experimental measurement $[11,16]$ indicating the validity and accuracy of the method used to calculate the value for SERR.

3.3. The Determination for Location of Potential Crack. In this section, we focus on the case in which the plain concrete beam was strengthened with CFRP externally bonded at the bottom surface to the beam. Under the load, there exist many cracks possibly initiated at the end of the CFRP or at the interface between concrete and CFRP. Such potential cracks in turn significantly influence the stability of the main crack. Consequently, the determination for the location of potential crack seems enormously important to investigate the increase or decrease in strength of a concrete beam bonded externally with CFRP.

As illustrated in Figure 3(b), the length of CFRP bonded at the bottom of the concrete beam is taken as $L_{0}=0.2 \mathrm{~m}$, the initial crack length $a_{0}$ is $20 \mathrm{~mm}$, and the length of the total concrete beam is $L=0.4 \mathrm{~m}$. For the convenience of comparison with experimental measurements, the load applied to the beam is $P=20 \mathrm{KN}$. Due to the symmetry of the model, half of the concrete beam was considered and performed in finite element analysis. According to [11], the maximum tensile stress for concrete material is $5.15 \mathrm{MPa}$. In terms of strength theory for brittle material, the concrete is considered to break or debond when the maximum tensile stress under the load in concrete beam exceeds the critical stress, $5.15 \mathrm{MPa}$. Figure 8 shows the distribution of maximum tensile stress in concrete beam, while the dark black region stands for the stress greater than critical stress value, that is, potential crack initiation. 


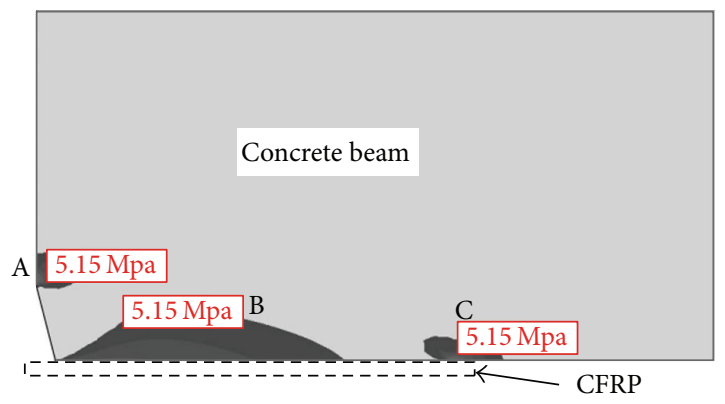

FIgURE 8: The distribution of the maximum tensile stress in the plain concrete beam strengthened with externally bonded CFRP.

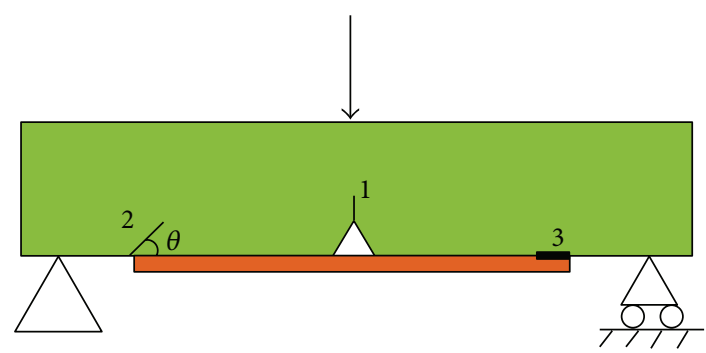

FIGURE 9: The potential crack initiation in concrete beam with CFRP.

Seen from the figure, the potential crack possibly occurs at three sites, near the main crack (denoted as A), at the interface between concrete and CFRP (denoted as B), and at the end of CFRP (denoted as C), respectively. For CFRP, it will not break through since the maximum tensile stress in CFRP is much smaller than its critical tensile stress, $4640 \mathrm{MPa}$. Subsequently, suppose that the strength of bonding between concrete material and epoxy resin and the bond force between expoxy resin and CFRP are sufficient enough to resist the tensile stress. The initiation of crack should occur at the side of the concrete beam. Therefore, the distribution of the potential crack in the concrete beam is sketched as in Figure 9. For the convenience of subsequent description, the main crack in the middle of the concrete beam, the crack probably initiated at the end of the CFRP, and the debonding cracks at the end of the CFRP are labeled as main crack 1 , inclined crack 2 , and delamination crack, respectively.

Cracks 1, 2, 3 illustrated in Figure 9 are possible to coexist at the same time, or one of them or both of them exist one time. Meanwhile, they will probably influence another to decrease the strength and the stiffness of the concrete beam.

3.4. The Effect of Main Crack Propagation on the Strengthened Beam. In order to investigate the effect of the main crack propagation on the performance of the strengthened beam, it is supposed in this section that the main crack only exists but the other cracks such cracks 2 and 3 did not.

Employing the similar method calculating SERR as previously described, SERR for the strengthened concrete beam is calculated, and the variation of SERR versus the main crack propagation in illustrated in as Figure 10. The horizontal line in figure with the value of $11.22 \mathrm{~J} / \mathrm{m}^{2}$ represents

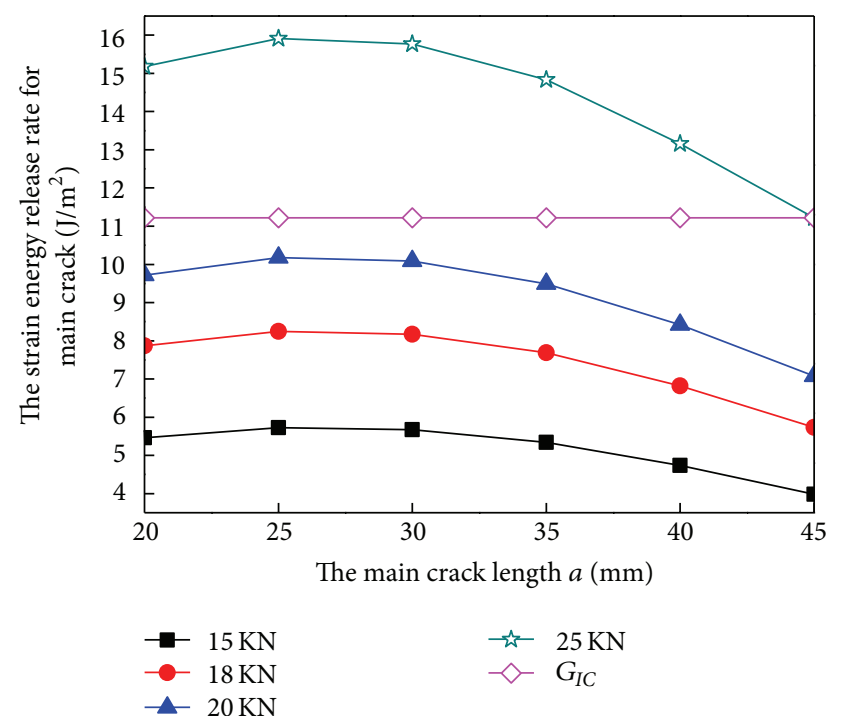

FIGURE 10: The plot of SERR against the main crack propagation.

the critical SERR for concrete material at which the concrete can probably break off. It can be seen from Figure 10 that when concrete beam is strengthened by CFRP, the SERR can significantly increase with the applied load, showing that the loading capacity of the beam is improved.

As the load increase to the extent at which SERR is greater than critical value, crack propagation will occur at the main crack. We can also find that the concrete beam strengthened with CFRP cannot sufficiently sustain the applied load at the initial stage of loading, because the main crack does not start to propagate and the subsequently increased load are mainly carried by concrete beam itself.

However, as the main crack extends to some certain length, CFRP begins to carry the load and the maximum tensile stress in CFRP starts to increase. As shown in Figure 10, for each load, SERR slightly increases as cracks extend but it decreases rapidly with crack propagation, and the case for load of $20 \mathrm{KN}$ strongly supports this point.

Figure 11 shows the comparison of SERR between before and after strengthening for various loads, 3000, 4000, and $5000 \mathrm{~N}$, respectively. From the figure, we can easily see that the strengthening beam with CFRP significantly improves the performance of the concrete beam, supported by the SERR for strengthened beam smaller than that without strengthening. The value of SERR for the beam with CFRP is almost 1/10 of that without CFRP. It is CFRP that decreases the value of SERR and increases the strength and stiffness of the concrete beam.

\subsection{The Effect of Main Crack Propagation on Inclined Crack}

3.5.1. The Determination for the Inclined Angle. Observed from Figure 9, as load applied at the midspan of the CFRP concrete beam increases, the deflection at the bottom of the concrete beam continually increases and CFRP bonded at the bottom of the beam starts to sustain the tension force. Since 


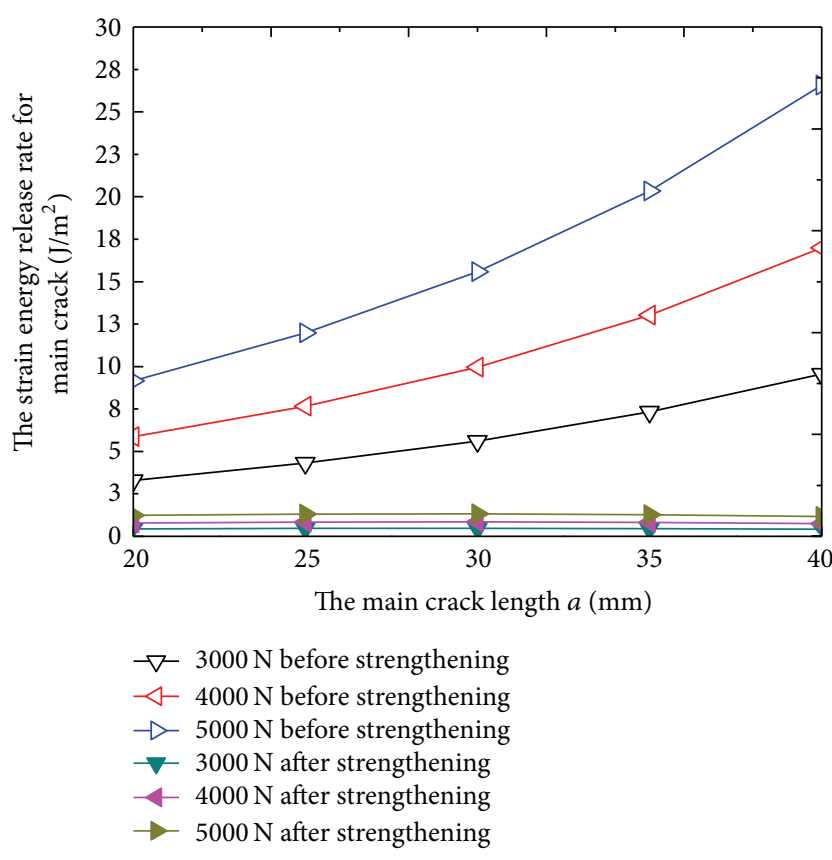

FIGURE 11: The comparison of SERR before and after strengthening.

the strength of CFRP is sufficient enough, it will not break due to a strength problem. The concrete material at the end of the CFRP can probably fail, and the inclined crack can initiate at this site. According to experiment observation, the direction of crack propagation makes an angle with the horizontal axis of a beam.

Based on the predication for crack path in bimaterial composites plate under uniform mechanical load and temperature load, suppose that an inclined crack can propagate along the direction of angle with the horizontal axis by the length of $\Delta a$, as illustrated in Figure 12.

The SERR for inclined crack extended by $\Delta a$ can be calculated as follows:

$$
\begin{gathered}
G_{\mathrm{I}}(a \longrightarrow a+\Delta a, \theta)=A \sin ^{2} \theta-B \sin \theta \cos \theta+C \cos ^{2} \theta \\
G_{\mathrm{II}}(a \longrightarrow a+\Delta a, \theta)=A \cos ^{2} \theta+B \sin \theta \cos \theta+C \sin ^{2} \theta \\
G(a+\Delta a, \theta)=G_{\mathrm{I}}(a \longrightarrow a+\Delta a, \theta) \\
+G_{\mathrm{II}}(a \longrightarrow a+\Delta a, \theta)=A+C,
\end{gathered}
$$

in which

$$
\begin{aligned}
& A=\frac{1}{2 t \Delta a}\left[F_{x}^{f}\left(u_{x}^{e}-u_{x}^{f}\right)+F_{x}^{h}\left(u_{x}^{g}-u_{x}^{h}\right)\right], \\
& B=\frac{1}{2 t \Delta a}\left[F_{x}^{f}\left(u_{y}^{e}-u_{y}^{f}\right)+F_{x}^{h}\left(u_{y}^{g}-u_{y}^{h}\right)\right. \\
& \left.+F_{y}^{f}\left(u_{x}^{e}-u_{x}^{f}\right)+F_{y}^{h}\left(u_{x}^{g}-u_{x}^{h}\right)\right], \\
& C=\frac{1}{2 t \Delta a}\left[F_{y}^{f}\left(u_{y}^{e}-u_{y}^{f}\right)+F_{y}^{h}\left(u_{y}^{g}-u_{y}^{h}\right)\right]
\end{aligned}
$$

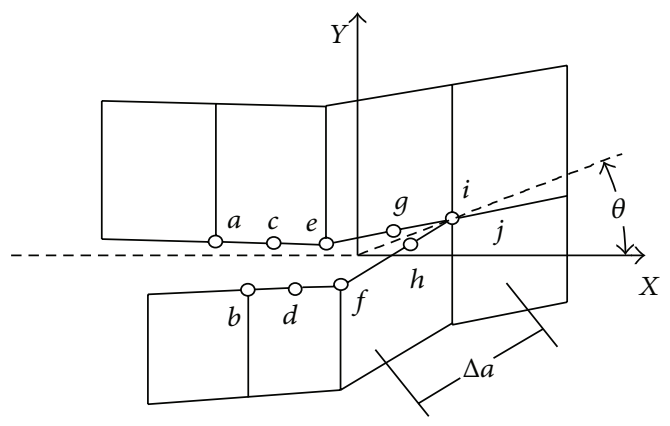

FIGURE 12: The finite element mesh configuration at the tip of crack with an angle against horizontal axis extended by the length of $\Delta a$.

in which $F_{x}^{i}, F_{y}^{i}(i=f, h)$ are the $x$ and $y$ components of nodal force at the node $i$ before the crack extends by $\Delta a$, and $u_{x}^{i}, u_{y}^{i}(i=e, f, g, h)$ are the $x$ and $y$ components of displacement at the node $i$ once crack extends by $\Delta a$.

Combined with the results from finite element analysis for concrete beam, the SERR of $G, G_{\text {I }}$, and $G_{\text {II }}$ can be easily calculated from (7)-(8). In terms of brittle fracture mechanics, the inclined crack always extends along the direction at which $G_{\text {II }}=0$ when $G_{I} \geq G_{I C}$. Since the angle is unknown, now an arbitrary angle is assumed and the angle is desired if it just makes $G_{\text {II }}=0$.

First, we forced $G_{\mathrm{II}}(\theta)$ to be zero to find a solution of the angle:

$$
G_{\text {II }}(\theta)=A \cos ^{2} \theta+B \sin \theta \cos \theta+C \sin ^{2} \theta=0 .
$$

In this case, the length of CFRP is $0.2 \mathrm{~m}$, the initial length of crack is $20 \mathrm{~mm}$, and the load is $20 \mathrm{KN}$. Substituting such known parameters into (7)-(9), we can obtain the solution to the angle, $\theta=45^{\circ}$ along which the inclined crack extends.

\subsubsection{The Effect of Main Crack Propagation on Inclined Crack.} In this section, the effects of main crack propagation on the inclined crack for various lengths of inclined crack have been discussed. Figures 13(a)-13(f) show the variation of SERR calculated at the inclined crack 2 with the propagation of main crack, (a) for the inclined crack length of $0 \mathrm{~mm}$, (b) for $1 \mathrm{~mm}$, (c) for $2 \mathrm{~mm}$, (d) for $3 \mathrm{~mm}$, (e) for $4 \mathrm{~mm}$, and (f) for $5 \mathrm{~mm}$, respectively. The increase in the inclined crack length means the progressive propagation of inclined crack as the load. The SERR calculated at the inclined crack is a good choice to reflect the influence of main crack propagation on the inclined crack and on the overall stiffness and strength of the concrete beam.

It can be seen from Figure 13 that for each given length of inclined crack, the value for SERR increases as the main crack grows, approaching the critical SERR of the concrete material and showing that the inclined crack with main crack propagation tends to crack. On the other hand, as illustrated in Figure 13(a), the value for SERR firstly appears to be a decrease as the main crack propagates, and then it seems to be an increase with the propagation of main crack, which implies that stress concentration exists in the concrete material at the end of the bonded FRP. As the main crack 


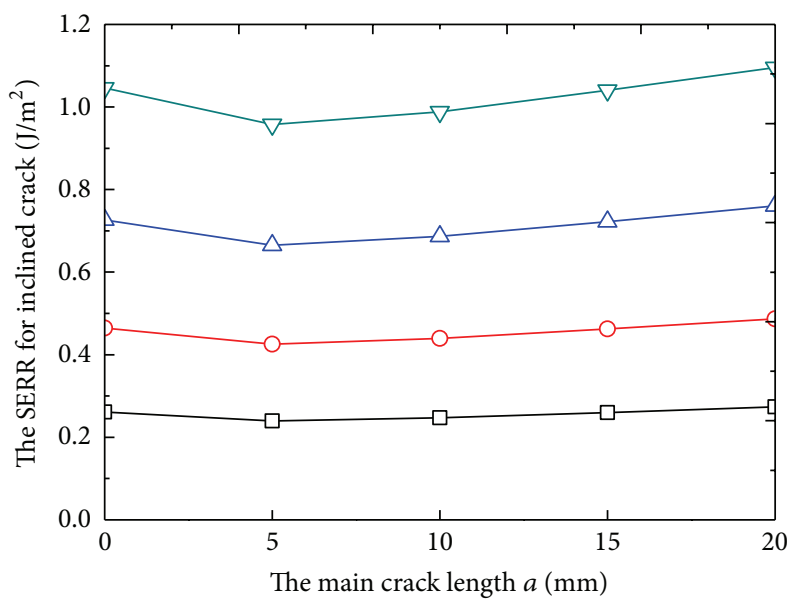

(a)

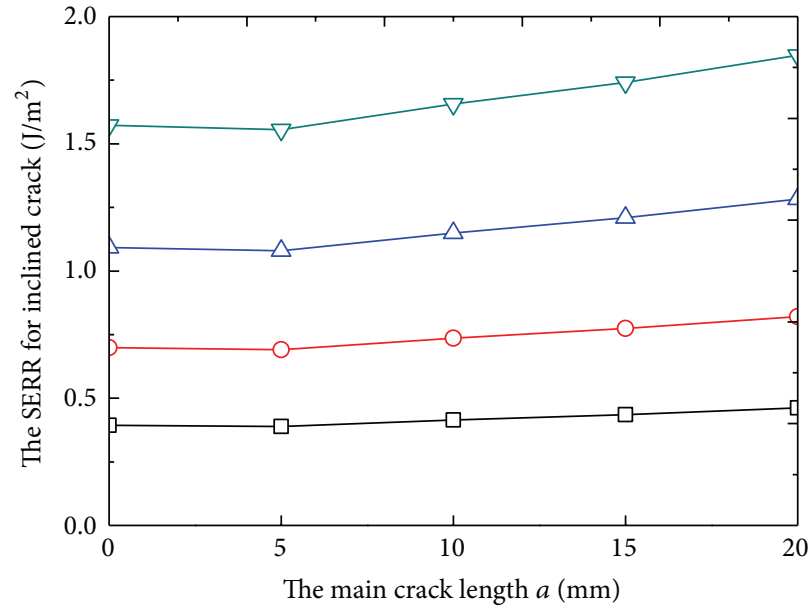

(c)

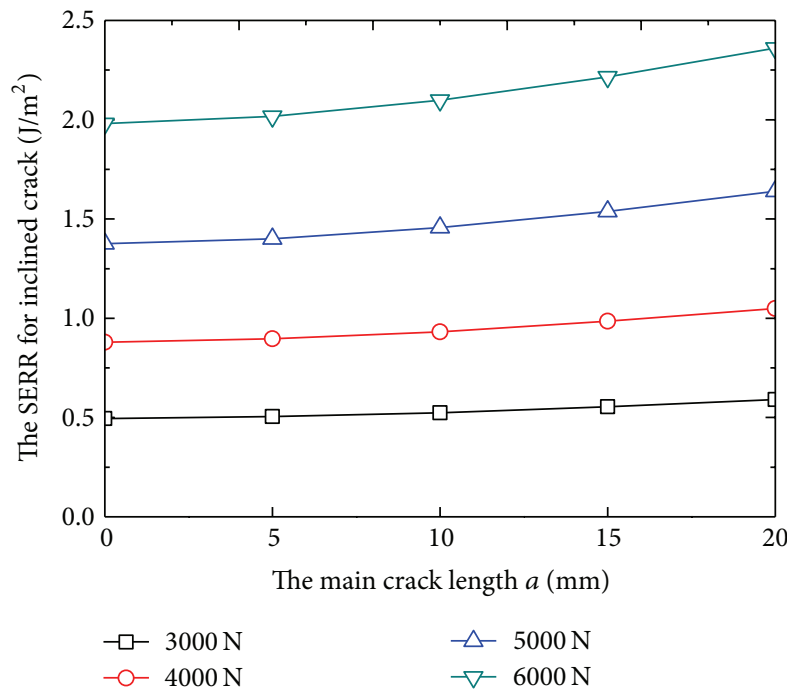

(e)

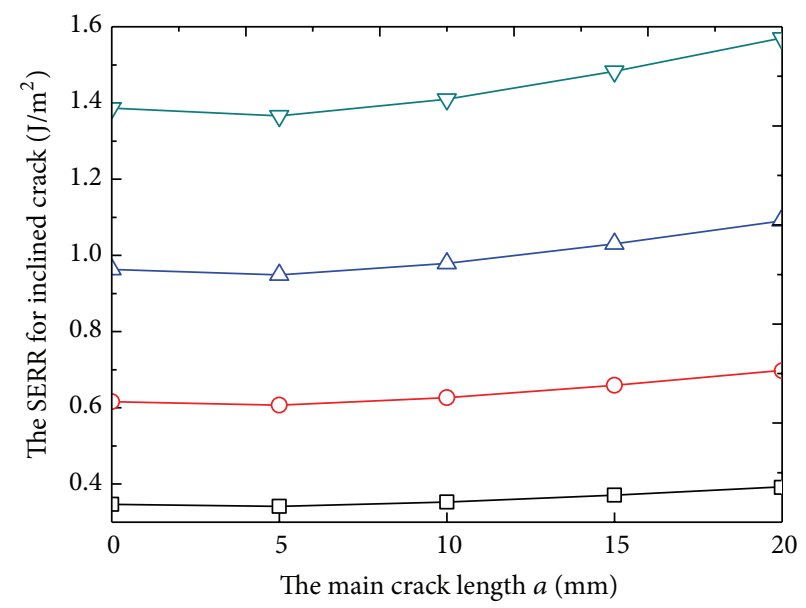

(b)

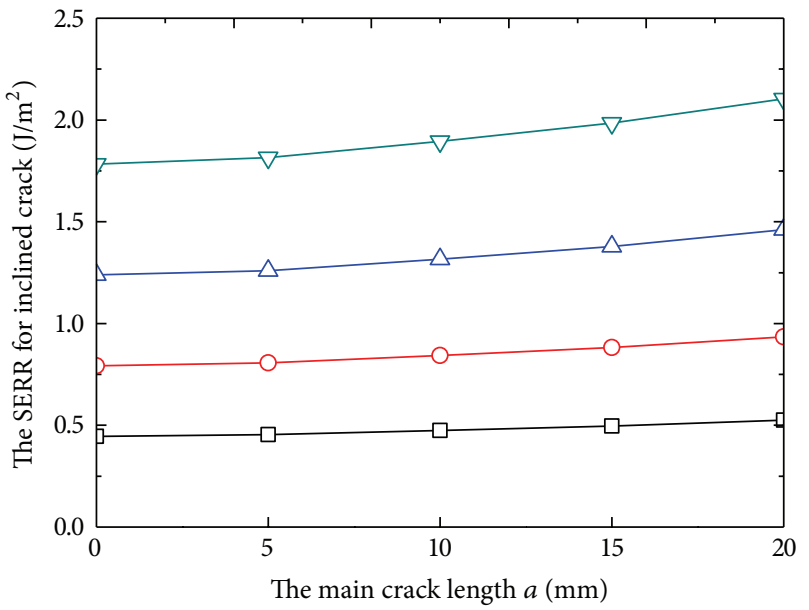

(d)

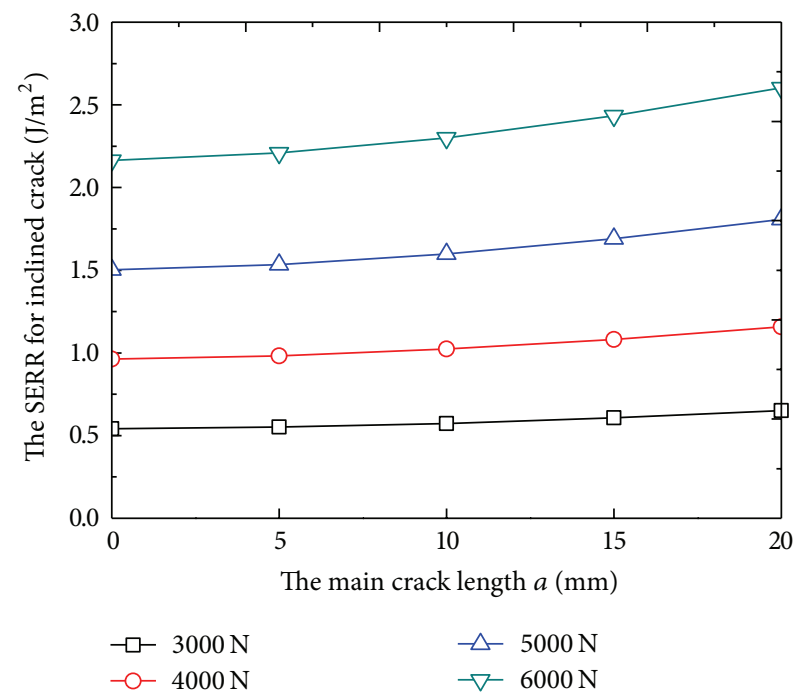

(f)

FIGURE 13: The plot of SERR against main crack propagation for various length of inclined crack. (a) $0 \mathrm{~mm}$ of inclined crack length, (b) $1 \mathrm{~mm}$ of inclined crack length, (c) $1 \mathrm{~mm}$ of inclined crack length, (d) $2 \mathrm{~mm}$ of inclined crack length, (e) $3 \mathrm{~mm}$ of inclined crack length, and (f) $0 \mathrm{~mm}$ of inclined crack length. 
does not propagate, the value for SERR at the end of the plate seems to be larger while it will decrease rapidly when main crack starts to propagate. Next, the phenomenon of stress concentration at the end of plate has been effectively released. Meanwhile, as the main crack progressively propagates to a fixed crack length, the magnitude of stress at the crack tip of the main crack can dramatically decrease due to the tension of FRP externally bonded at the bottom of the concrete beam. At this time, CFRP begins to become tensile more than before and it considerably releases the stress concentration occurring at the main crack. The higher tension in CFRP due to its high stiffness and modulus can effectively prevent the main crack in concrete beam from propagating continually. However, SERR for inclined crack in turn increases slightly because the tensile stress in CFRP drastically increases the concentration of stress at the end of CFRP, building up the risk of crack propagation. With the inclined crack proceeding to propagate, the value for SERR at the inclined crack tends to increase slightly regardless of the applied load, seen from Figures 13(a)-13(f), showing that the propagation of inclined crack makes the SERR for itself much closer to the critical value and increases the risk of crack formation.

\section{Conclusion}

The concrete beams with and without CFRP strengthened are considered to investigate the improvement in loading capacity and analyze the failure mechanism of the concrete beam. The main conclusions can be drawn as follows.

(1) Strain energy release rate (SERR) for a specified crack has been chosen as an indicator to show the strengthening effect of CFRP bonded at the bottom of concrete beams. The strain energy release rate are calculated at an interest crack based on virtual crack closure technology (VCCT) using FEM to determine whether the mechanical properties of the beam are strengthened by being externally bonded with CFRP.

(2) For plain concrete beam without being strengthened by CFRP, the calculated SERR for any case of load can increase slightly with the main crack propagation. The bigger the magnitude of SERR is, the closer it approaches $G_{C}$ of the concrete material. It implies that the strength of the beam decreases with the increase of SERR.

(3) For plain concrete beam externally bonded with CFRP, the value for SERR can significantly increase with the applied load, showing that the loading capacity of the beam is improved. However, as the main crack extends to some certain length, the value for SERR slightly increases as cracks extend, but it decreases rapidly with crack propagation.

\section{Acknowledgments}

This work is financially supported by the Natural Science Foundation of China (11302272), by the Natural Science Foundation of China (11272368), by the Natural Science
Foundation Project of Chongqing Municipality (CSTC, 2010BB4085), and by the Science and Technology Project Affiliated to the Education Department of Chongqing Municipality ( KJ120801).

\section{References}

[1] A. K. M. Anwarul Islam, "Effective methods of using CFRP bars in shear strengthening of concrete girders," Engineering Structures, vol. 31, no. 3, pp. 709-714, 2009.

[2] M. C. Sundarraja and S. Rajamohan, "Strengthening of RC beams in shear using GFRP inclined strips-an experimental study," Construction and Building Materials, vol. 23, no. 2, pp. 856-864, 2009.

[3] H. C. Biscaia, C. Chastre, and M. A. G. Silva, "Nolinear numerical analysis of the debonding failure process of FRP-to-concrete interfaces," Composites B, vol. 50, pp. 210-223, 2013.

[4] J. Michels, R. Christen, and D. Waldmann, "Experimental and numerical investigation on postcracking behavior of steel fiber reinforced concrete," Engineering Fracture Mechanics, vol. 98, pp. 326-349, 2013.

[5] X.-S. Yang, J. M. Lees, and C. T. Morley, "Modelling crack propagation in structures: comparison of numerical methods," Communications in Numerical Methods in Engineering, vol. 24, no. 11, pp. 1373-1392, 2008.

[6] J. F. . Guan, L. B. Qing, and S. B. Zhao, "Research on numerical simulation on the whole cracking processes of three-point bending notch concrete beams," Chinese Journal of Computational Mechanics, vol. 30, pp. 143-148, 2013.

[7] S. S. Pendhari, T. Kant, and Y. M. Desai, "Application of polymer composites in civil construction: a general review," Composite Structures, vol. 84, no. 2, pp. 114-124, 2008.

[8] C. Mazzotti, M. Savoia, and B. Ferracuti, "An experimental study on delamination of FRP plates bonded to concrete," Construction and Building Materials, vol. 22, no. 7, pp. 1409-1421, 2008.

[9] W. Xue, L. Zeng, and Y. Tan, "Experimental studies on bond behaviour of high strength CFRP plates," Composites B, vol. 39, no. 4, pp. 592-603, 2008.

[10] J. Valivonis and T. Skuturna, "Cracking and strength of reinforced concrete structures in flexure strengthened with carbon fibre laminates," Journal of Civil Engineering and Management, vol. 13, no. 4, pp. 317-323, 2007.

[11] S. S. Niu, The experimental study on concrete beams strengthened with CFRP [M.S. thesis], Chongqing University, Chongqing, China, 2008.

[12] T. L. Anderson, Fracture Mechanics: Fundamentals and Applications, CRC Press, 2005.

[13] A. M. Navier, Material Properties of Concrete, China Building Industry Press, 2011.

[14] R. Krueger, "Virtual crack closure technique: history, approach, and applications," Applied Mechanics Reviews, vol. 57, no. 1-6, pp. 109-143, 2004.

[15] J. Ding, Crack failure study of CFRP reinforced concrete beams [M.S. thesis], Chongqing University, Chongqing, China, 2008.

[16] K. P. Herrmann and M. Dong, "Thermal cracking of two-phase composite structures under uniform and non-uniform temperature distributions," International Journal of Solids and Structures, vol. 29, no. 14-15, pp. 1789-1812, 1992. 

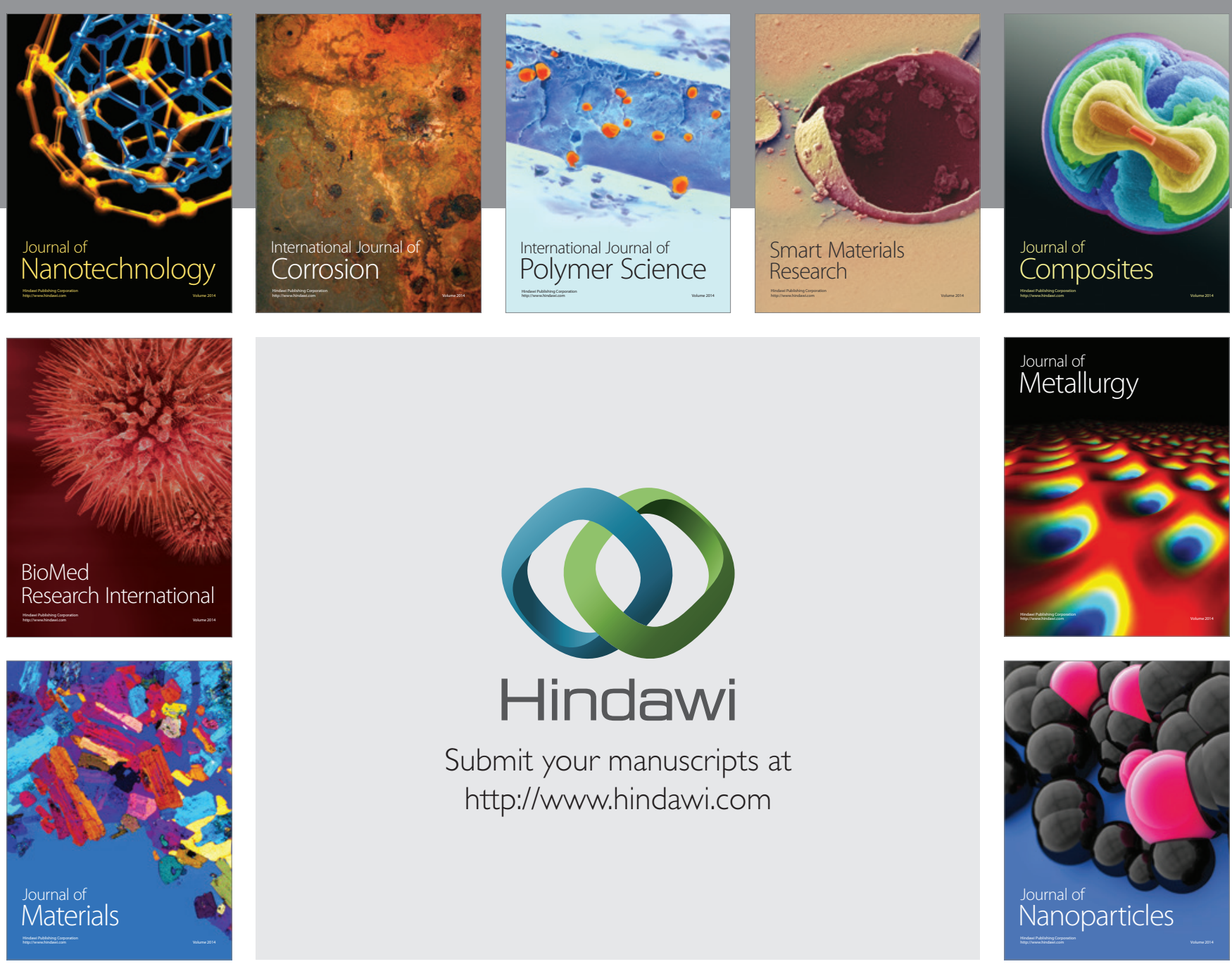

Submit your manuscripts at http://www.hindawi.com
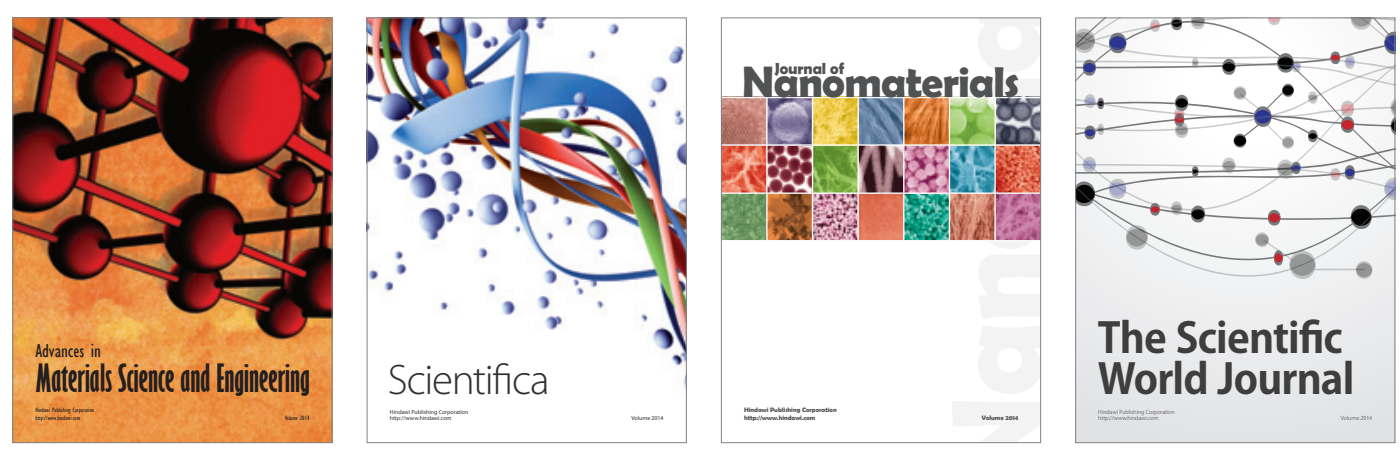

\section{The Scientific World Journal}
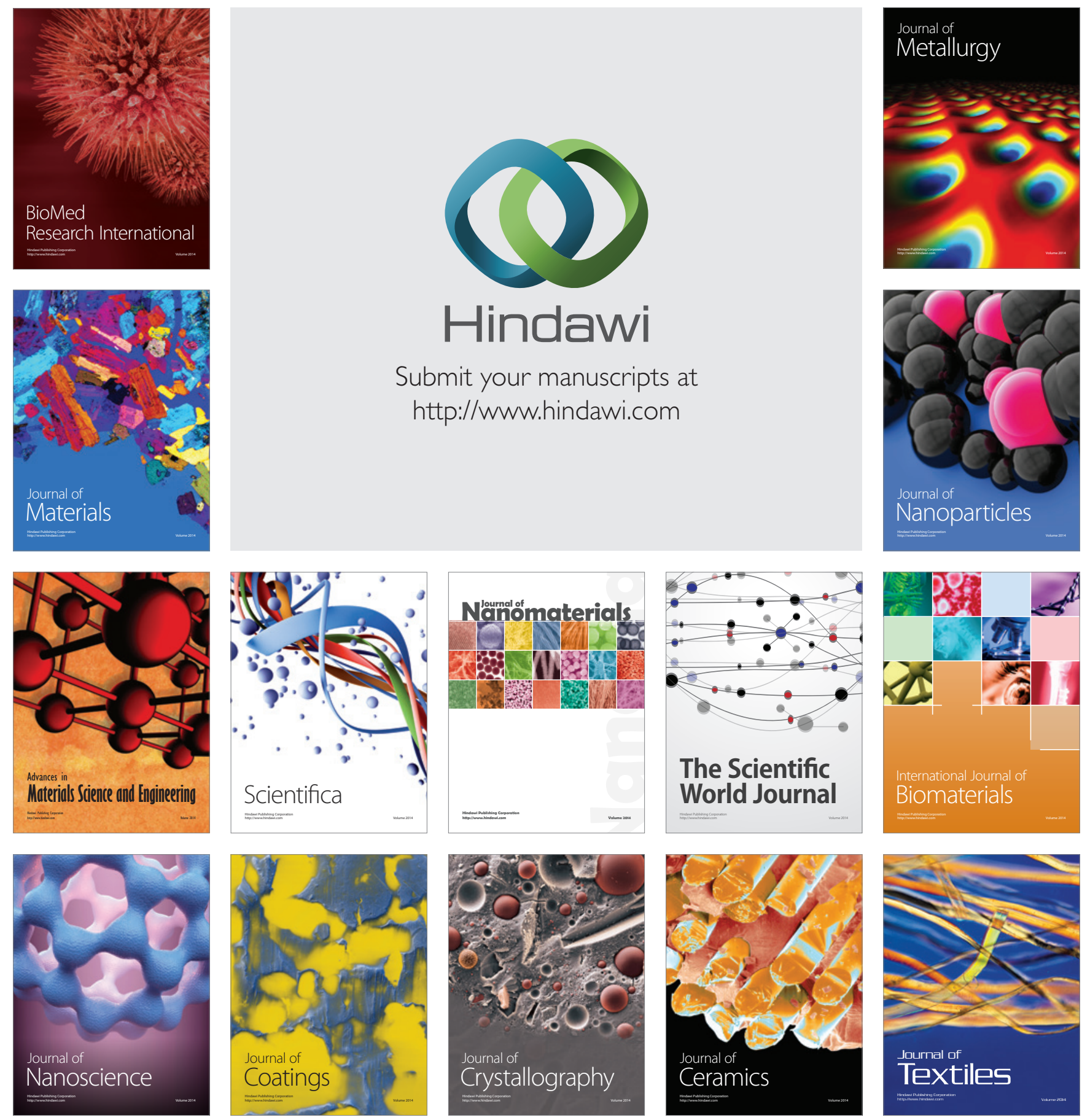